\title{
Growth and Biomass in Response to Salinity and Subsequent Fresh Water in Mangrove Seedlings Avicennia marina and Rhizophora stylosa
}

\section{Mohammad Basyuni ${ }^{1}$, Lollie Agustina Pancawaraswati Putri ${ }^{2}$, Berliana Nainggolan ${ }^{1}$, Putri Ester Sihaloho ${ }^{1}$}

\author{
${ }^{1}$ Department of Forestry, Faculty of Agriculture, Jl. Tri Dharma Ujung No. 1 Kampus USU Medan, \\ University of Sumatra Utara, Medan, Indonesia 20155 \\ ${ }^{2}$ Department of Agroecotechnology, Faculty of Agriculture, Jl. Prof. A. Sofyan No. 3 Kampus USU Medan, \\ University of Sumatra Utara, Medan, Indonesia 20155
}

Received December 7, 2013/Accepted March 21, 2014

\begin{abstract}
The present study describes the growth and biomass of salt secretor mangrove, Avicennia marina and the nonsecretor Rhizophora stylosa by long-term exposure to salinity and its subsequent fresh water. The seedlings of the 2 mangroves grown with varying salt concentration for 3 months were then divided into 2 treatment groups, and grown for another 3 months: 1 continuously in salinity conditions and another in fresh water to recover from salinity. The growth parameter namely plant height and diameter of A. marina was significantly enhanced by salt with maximal stimulation at 2\% (equal to $75 \%$ natural seawater) and this increase appeared to be attenuated by increasing the salinity concentration above $2 \%$. By contrast, the growth of R. stylosa significantly thrived up to $0.5 \%$ salt concentration, then decreased with the increasing of salinity. The growth of both species slightly increased after removal to salinity. Our findings suggested that within the range of salinity treatments, A. marina was more salt tolerant than $R$. stylosa, which provides important information for mangrove rehabilitation in North Sumatra. The biomass of the 2 mangrove seedlings was changed in the same manner as the growth of plants upon salt and fresh water treatment. These results suggested the importance of mangrove adaptation withstand salt and/or water stress.
\end{abstract}

Keywords: mangrove zonation, re-adaptation, rehabilitation, salt stress, water stress

*Correspondenceauthor,email:m.basyuni@usu.ac.id, tel./fax.: +62-61-8201920

\section{Introduction}

Indonesia is one of the world's great mangrove nations, which is $22.6 \%$ of the global total (Giri et al. 2011). Mangrove plants comprise a heterogeneous group of independently derived lineages that are defined ecologically by their location in upper inter-tidal zones of tropical and subtropical climates and physiologically by their ability to withstand high concentrations of salt or low levels of soil aeration (Basyuni et al. 2007). The zonation pattern of mangrove species is related to the extent and severity of soil waterlogging and salinity, which, in turn, are influenced by the frequency and duration of inundation by sea water and fresh water seepage (Lugo \& Snedaker 1974). Mangrove plants tolerate salinity of the soil and water was distinguished by 2 groups with regard to salt tolerance mechanism (Scholander et al. 1962; Tomlinson 1986). The first group is the salt-secreting species, exemplified by Avicennia marina, have either salt glands or salt hairs to remove excess salt. The second one is non-secreting species, including Rhizophora stylosa, do not have such morphological features for excretion of excess salt. A. marina and R. stylosa are common mangrove species in North Sumatra, Indonesia and are considered to be representative of each group.

Mangroves are one of the most threatened ecosystems all over the world today due to direct and indirect degradation
(Duke et al. 2007). Conservation of mangrove implicates not only to protect the coastal areas and communities from seawater intrusion and potential changes in sea level rise but also to ensure the availability of resources for future use through adaptation to changing environments. However, there is relatively little information on the recovery process of the seedling growth of mangrove when salinity is readapted with fresh water after a long period of salinization. Our previous studies shed light on the triterpenoid content and gene expressions of triterpenoid synthases in salt-treated and re-adapted mangrove plants (Oku et al. 2003; Basyuni et al. 2009;2011;2012a; b)

Mangroves are salt tolerant plant and it is therefore important to get more insight into the morphological aspects not only to cope with salinity but also to withstand the water stress after the recovery from high salinity. Such studies could be noteworthy to mangrove tree species, which may experience transient periods of exposure to high salt concentrations. Moreover, this information is important to the success of rehabilitation and conservation effort in North Sumatra. Thus, the aim of our present work is to investigate the growth and biomass responses of the salt-secretor mangrove seedling, A. marina in comparison to that of the non-secretor species $R$. stylosa by long-term exposure to salinity and its subsequent recovery to fresh water. 


\section{Methods}

Mature and healthy propagules of A. marina (Forsk.) Vieh (Acanthaceae) and R. stylosa Griff. (Rhizophoraceae) were collected from the Belawan Coast, Medan, North Sumatra, Indonesia and planted in bottle pots with sand under varied salinity for 3 months with exposure to natural temperature and sunlight in a greenhouse of Faculty of Agriculture, University of Sumatera Utara, Medan, Indonesia. Mature propagules of $A$. marina were pericarp green in colour, $1.5-2.5 \mathrm{~cm}$ lenght, and $1.5-2.0 \mathrm{~cm}$ width, while mature propagules of $R$. stylosa were yellowish green in colour, $20-30 \mathrm{~cm}$ lenght, and $1.5-2.0 \mathrm{~cm}$ diameter. An artificial seawater solution was prepared by dissolving a commercial salt powder (marine salts) to adjust the salinity concentrations to $0.0,0.5,1.5,2.0$, and $3.0 \%$ (equal to sea water level) according to the manufacturer's protocol. Each pot was irrigated with $1000 \mathrm{~m} \ell$ artificial seawater solution. The salinity in this study was defined as the mass of salt powder/mass of solution (Basyuni et al. 2009). In each pot, the treatment of salt concentration was checked every week during the experiments using an S/Mill-E salinity refractometer, and replaced with freshly prepared seawater solution to maintain a constant salt concentration throughout the study.

After 3 months of cultivation under vary salinity, these seedlings were then divided into 2 treatment groups, and grown for another 3 months: 1 group continuously in salt solution and the other in fresh water to recover the salinity. At this step, fresh water was applied to the second group several times to leach the salinity solution from the root systems before the re-adaptation period to fresh water was started. After 6 months of growth, the 2 species were harvested and washed, and the leaves, shoots and roots were stored at $-4{ }^{\circ} \mathrm{C}$ for further analysis.

Growth measurement Growth of $A$. marina and $R$. stylosa seedlings under varying salt concentration and subsequent recovery to fresh water was determined by the stem height and diameter of the plants. Thus, the stem heights and diameters of $A$. marina (3-18 seedlings) and $R$. stylosa (3-24 seedlings) after 6 months of cultivation were the indices of growth in this study.

Number of leaves and leaf areas measurement Calculation on the number of leaves was performed at 6 month old mangrove seedlings shortly before harvesting. Data collection was conducted simultaneously with data collection of seedling height and diameter. To measure the leaf area, the top 2 expanded leaves were collected from control. Salt-treated, and recovered seedling leaves were digitally scanned to quantify leaf area using ImageJ software (Schneider et al.2012).

Biomass measurement Biomass was determined by destructive sampling techniques. Two mangrove seedlings were partitioned into leaf, stem and root components to weigh prior to drying. The seedling biomass was measured from dry weights of leaves, shoots and roots of each plant which were determined separately on an analytical balance, after drying in an oven at $75^{\circ} \mathrm{C}$ for $48 \mathrm{~h}$. The weights recorded once a constant weight was reached. From these measurements, we calculated wet and dry weight of leaves, stems and roots of seedling individual of both species.

Statistic analysis The data were analyzed by one-way analysis of variance (ANOVA) followed by Dunnett's test for comparisons of all treatments (salt-treated or re-adapted) against the control. The values of $p<0.01$ and $p<0.05$ were selected as the thresholds of statistical significance. All of the statistical analyses were performed using the SAS 9.1 statistical software program (SAS Institute Inc., Cary, NC, USA).

\section{Results and Discussion}

Effect of salinity and its subsequent recovery on the seedling growth The seedling growth parameter was measured by the height and diameter of $A$. marina, a salt secretor species, was significantly enhanced by salt with maximal stimulation at $2.0 \%$ (equal to $75 \%$ natural seawater). This increase appeared to be attenuated by increasing the salinity concentration above $2.0 \%$ (Figure 1 a$\mathrm{b}$, column 1.5 , and $2.0 \%$ ). The growth of $A$. marina slightly increased after removal to salinity (re-adaptation) (Figure 1 $\mathrm{a}-\mathrm{b})$.

By contrast, the growth of $R$. stylosa, a non-secretor species, significantly thrived up to $0.5 \%$ salt concentration, and then decreased with increasing salinity (Figure $2 \mathrm{a}-\mathrm{b}$ ). Interestingly, seedling growth of both species was slightly lower in saline conditions comparing to that recovery into fresh water (Figure 1, Figure $2 \mathrm{a}-\mathrm{b}$, column $0.5 \% \rightarrow 0.0 \%$, $1.5 \% \rightarrow 0.0 \%$ and $2.0 \% \rightarrow 0.0 \%$ ). In the case of the plant height and diameter at higher salinity (3\% salt concentration) there was no difference with the control except in R. stylosa where significantly growth inhibition was noted (Figure 1, Figure 2 a-b). Plants were tallest in R. stylosa $(195.8 \mathrm{~mm}$ at $0.0 \%$ salinity) comparing to A marina (166.1 mm at $2.0 \%$ salt concentration), on the other hand the $R$. stylosa diameter (4.7 $\mathrm{mm}$ at $0.5 \%$ salinity) was bigger than $A$. marina (2.7 at 1.5 and $2.0 \%$ salt concentration).

Salinity is one of the most important drivers in mangrove establishment and early development (Ball 2002; Krauss et al. 2008). Number of studies has been reported that mangrove seedlings often show growth stimulation at low salinity $(25 \%$ seawater or $0.5 \%$ salt concentration) and moderate salinity (50\% seawater $1.5 \%$ salinity) and then a decline in growth with further elevates in salinity, although optimum salinity has been shown to vary with seedling age (Downton 1982; Clough 1984; Naidoo 1987; Ball 1988; Burchett et al. 1989; Khan \& Aziz 2001; Ball 2002). Despite living in a saline environment, most mangrove species also grow in fresh water, but their growth is promoted by saline conditions, with the optimal salinities ranging 5-50\% seawater for best growth (Clough 1984; Ball 1988). As depicted in Figure 1 and Figure $2 \mathrm{a}-\mathrm{b}(0 \%$ salt concentration or fresh water), slow growth in fresh water is often attributed to the inability of halophytes to accumulate inorganic ions in sufficient quantities for osmo-regulation when the 


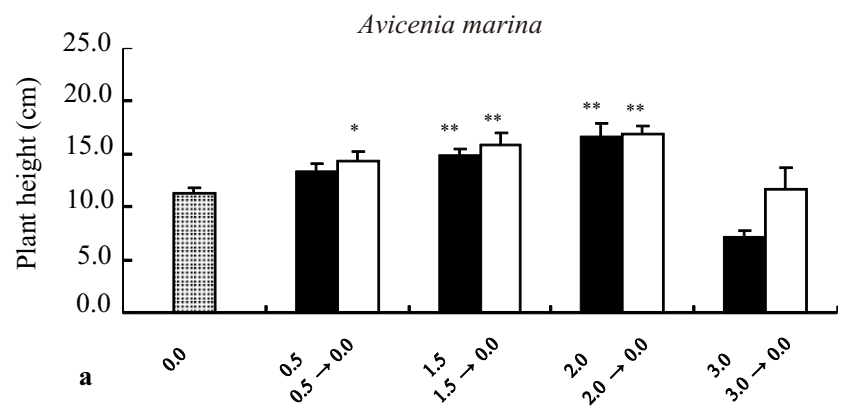

Salt concentration $(\%)$

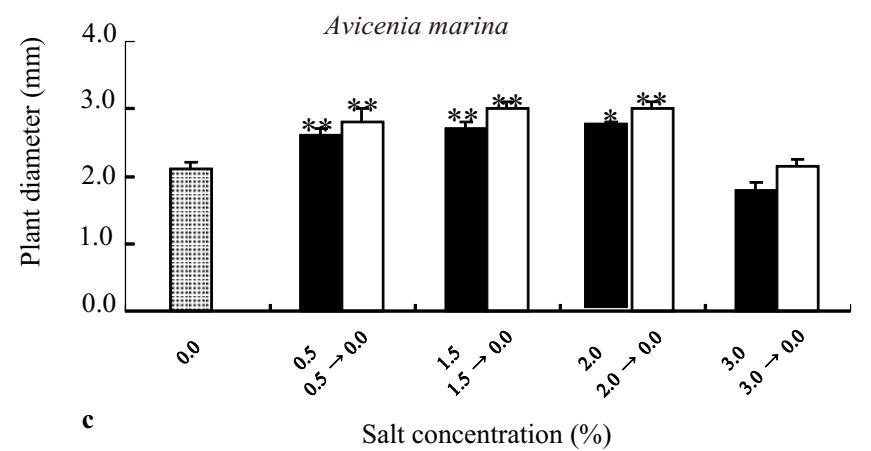

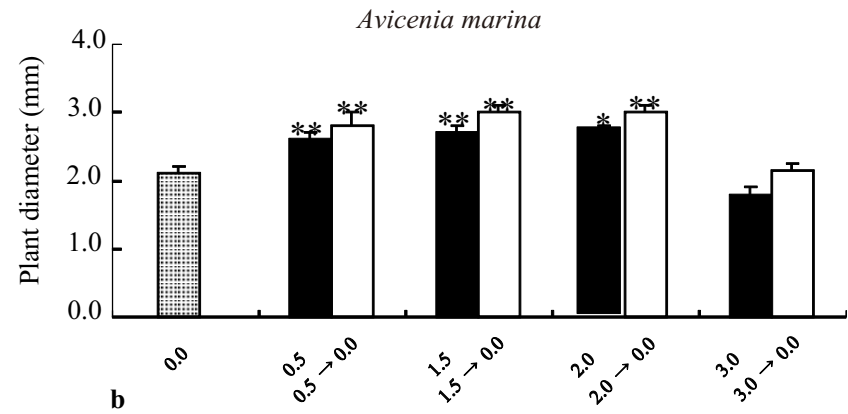

Salt concentration (\%)

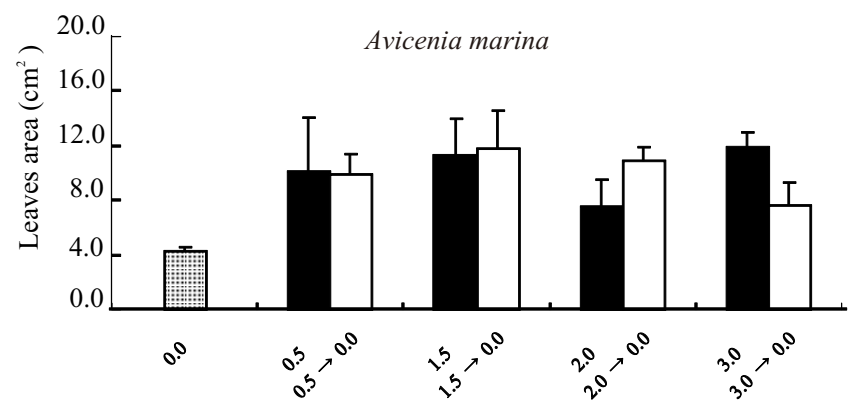

d

Salt concentration (\%)

Figure 1 Effect of salinity and subsequent re-adaptation to fresh water on height (a), diameter (b), number of leaves (c), and leaves area (d) of Avicenia marina seedlings. The data are expressed as the means $\pm \mathrm{SE}(n=3-18) ; * * P<0.01, * P<0.05$ compared with the control group $(0 \%)$ by Dunnett's test. Control (四), salinity ( $\square)$, re-adapted $(\square)$.
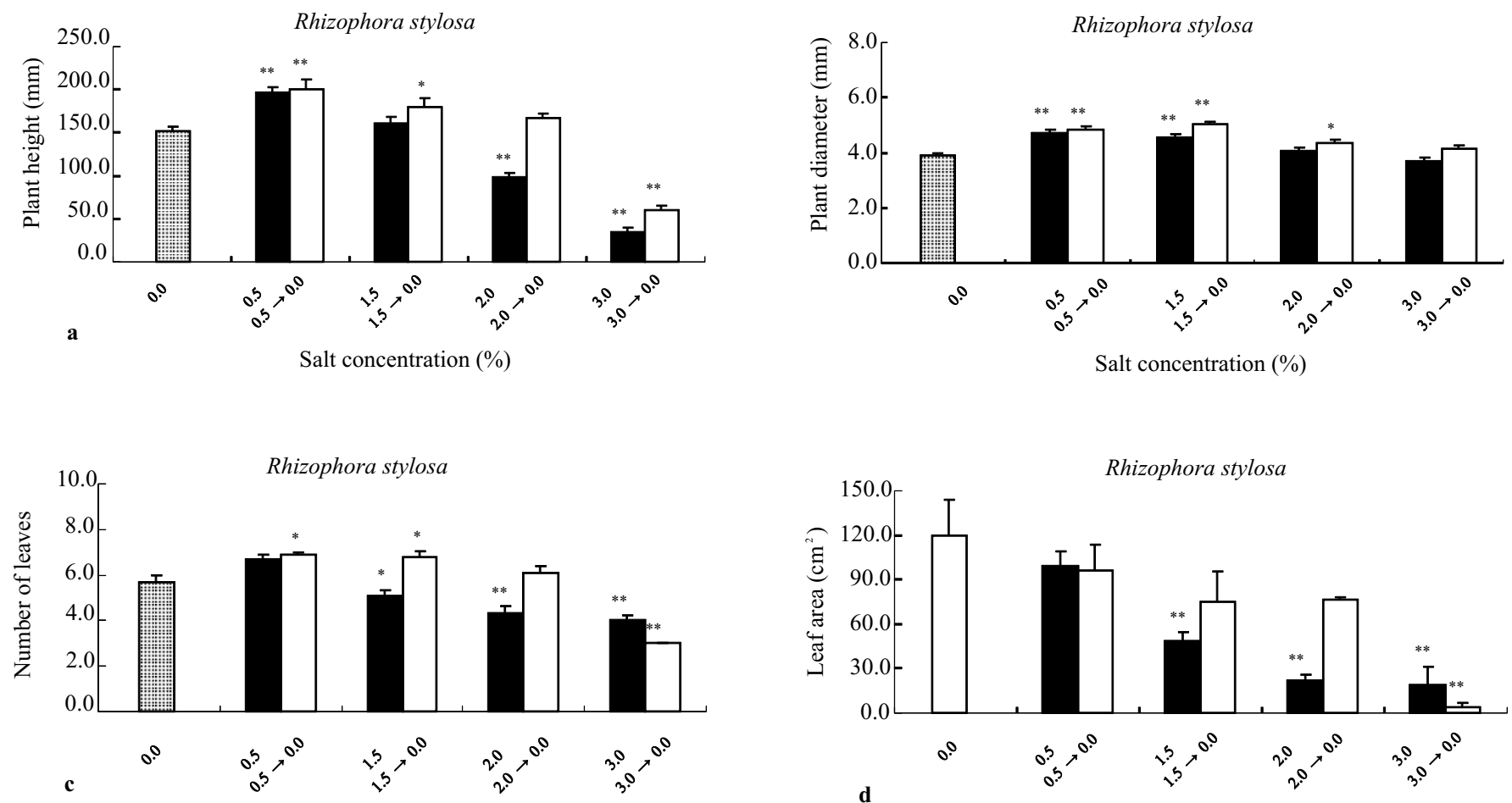

Salt concentration $(\%)$

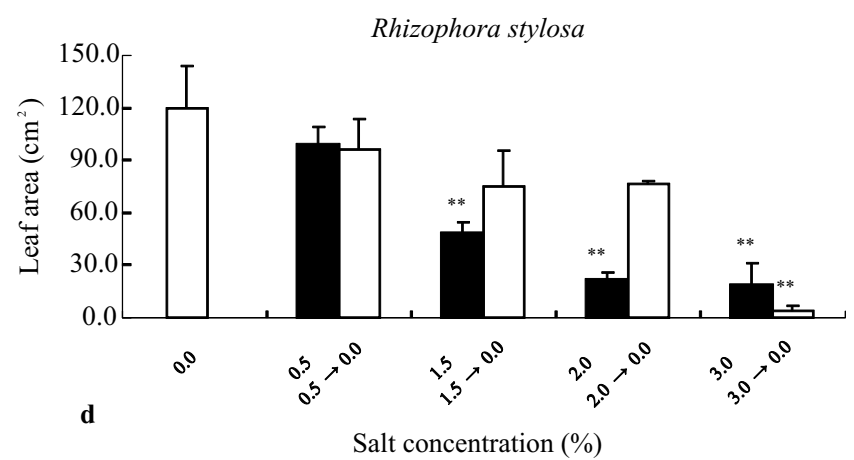

Figure 2 Effect of salinity and subsequent re-adaptation to fresh water on height (a), diameter (b), number of leaves (c), and leaves area (d) of Rhizophora stylosa seedlings. The data are expressed as the means \pm SE $(n=3-24) ; * * P<0.01, * P<0.05$

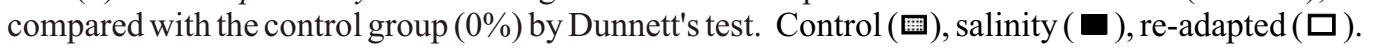


substrate is lacking in sodium chloride (Clough 1984; Flowers \& Colmer 2008). Furthermore, a number of experimental studies have shown reduced growth in mangrove seedlings in fresh water (Downton 1982; Clough 1984). It has been established that mangroves must maintain tissue water potential below the osmotic potential of the very salty substrate (Naidoo 2006). However, the range of salinity in which the mangrove plant is able to survive varies according to the speciesspecific and seedling growth stage (Krauss et al. 2008; Krauss \& Ball 2013).

The mangrove species display a universal of growth responses to salinity. The growth $A$. marina was significantly increased by salt with maximal stimulation at $2.0 \%$ and this increase to be weakened by increasing the salinity above $2.0 \%$. In contrast to this observation, the growth of $R$. stylosa significantly advanced to $0.5 \%$ salt concentration, and then decreased with increasing salinity. These results of greenhouse experiments are also consistent with the previous reports on the optimal growth at $50 \%$ salinity in Kandelia candel and Bruguiera gymnorrhiza seedlings (Basyuni et al. 2009), and low to moderate salt concentration $(7.5-15.0 \mathrm{ppt})$ found in $R$. mucronata, B. gymnorrhiza, and A. marina (Hutahaen et al. 1999). Ball (1988) showed that $A$. marina is a salttolerant mangrove with the competitive ability to grow in highly saline and poorly inundated locations. It has been reported that Ceriops tagal, $R$. mucronata, and A. marina from Pakistan showed an optimal growth at $50 \%$ seawater salinity (Khan \& Aziz 2001). Mangroves are a type of facultative halophyte, however, their seedlings stage are likely the most sensitive in growth and development (Krauss et al. 2008; Krauss \& Ball 2013). A saline substrate is important in mangrove development and affects many aspects of their growth and physiology (Downton 1982; Clough 1984; Ball 1988). As in the case with many other halophytes, which grow poorly in a culture medium that lacks sodium chloride (Flowers \& Colmer 2008). However, in mangrove plants, their seedling stage is the stage of higher salt tolerance (Wang et al. 2011), due to their propagules store large amount of energy and nutrient (Tomlinson 1986; Yan et al. 2007). There have been several studies to report this advantage provides the seedlings with abundant nutrients and energy to support their early growth under nutrient-poor or saltstressed conditions (Wang et al. 2002; Yan et al. 2007; Krauss et al. 2008).

Growth and survival of halophytes are dependent on the high levels of ion accumulation in its tissue for the maintenance of turgor and osmotic adjustment (Flowers \& Colmer 2008). Salinity in the mangrove environment is due largely to $\mathrm{NaCl}$ and varying in time and space from freshwater to hypersaline conditions (Krauss \& Ball 2013). Different growth responses to fresh water between $A$. marina and $R$. stylosa indicated that these two mangrove species had different tolerance to water stress. These results suggested that both mangrove seedlings survived to adapt either in saline or fresh water.
Mangroves can grow in a range of salinities, from primarily freshwater environments into hypersaline regions (Tomlinson 1986; Krauss et al. 2008). Our present data provides information on the growth seedling under varying salinities and subsequent re-adaptation to fresh water, which is important factor for mangrove distribution. Because of its position along the land-sea interface, mangrove is highly vulnerable to abrupt changes in sea level and river sediment load as well as threatened by climate change (Duke et al. 2007; Gilman et al. 2008). Sea level rise will increase salinity when tides push up further into estuaries, there will be longer inundation cycles and changes in the intertidal region (Feller et al. 2010). Thus, the present-day, human induced, rapid environmental changes demand a better understanding of the dynamic of the mangrove ecosystem.

Salinity therefore plays an important role on the adaptation of mangrove growth. The adaptation of mangrove growth will be also affected by nutrient (concentration, distribution, ecological coastal system). The salinity is related with sedimentation system and also water circulation (physical oceanography). Seedling growth and establishment would extend mangrove distribution and increase mangrove rehabilitation as well as land establishment. Although most mangrove propagules can tolerate a broad variety of salinities, the persistence and exposure to physical and physiological desiccation increases with increased salinity (Tomlinson 1986; Krauss et al. 2008). Seedlings of halophytes can obtain the elements for their growth demands from soil or from the propagules themselves in the case of viviparous mangroves, for instance in R. stylosa (Tomlinson 1986). On the other hand, A. marina, a cryptoviviparous mangrove, the cotyledons may act as a sink for ions and nutrients supporting the seedlings in their early growth in the saline condition (Wang et al. 2002; Yan et al. 2007).

Effect of salinity and its subsequent recovery on the number of leaves and leaf areas Salinity and removal from salinity had no consistent effect on the number of leaves in $A$. marina except increased significantly at $0.5 \%$ salt concentration (Figure 1c). This result well agrees with previously has been reported that salinity had no effect on number of leaves and leaves are per seedling of $R$. mucronata in India (Kathiresan \& Rajendran 2002). In contrast to this observation, salinity and its subsequent recovery affected number of leaves in R.stylosa as shown in Figure 2c.

Salinity significantly decreased the number of leaves, on the other hand, number of leaves of $R$. stylosa enhanced by re-adaptation from salinity (Figure $2 \mathrm{c}$, column $0.5 \% \rightarrow$ $0.0 \%, 1.5 \% \rightarrow 0.0 \%$ and $2.0 \% \rightarrow 0.0 \%$ ). No significant change was noted in the leaves area of $A$. marina with salinity or after removal, as shown in Figure 1d. Contrary to the $A$. marina seedling, salinity significantly decreased the leaves area of $R$. stylosa and similarly, re-adaptation from salinity significantly decreased leaves area only at $2.0 \% \rightarrow 0.0 \%$ (Figure $2 \mathrm{~d}$ ). 
Khan \& Aziz (2001) reported that $A$. marina accumulated the highest concentrations of ions followed by $R$. mucronata and C. tagal. Our previous results showed that salt stress significantly increased the concentration of $\mathrm{Na}^{+}$in the leaf of $K$. candel and B. gymnorrhiza. The sodium content of $B$. gymnorrhiza was higher than that of $K$. candel throughout the salinity treatment (Basyuni et al. 2009). A. marina has the ability to regulate salt content by secreting it through the glands, while $R$. stylosa has the ability to exclude salts via root ultrafiltration (Scholander et al. 1962; Tomlinson 1986) but do not have the ability to secrete salt through leaves. Accordingly, salt-secreting mangroves have higher metabolic and nutritional demands than non-salt-secreting species, a tradeoff against higher growth rates at lower salinity conditions (Ball 1988, 2002; Krauss et al. 2008).

To prevent the accumulation of salt, $A$. marina seedlings remove it through the gland. These seedlings responded with a high salt concentration in leaves by producing relatively large quantities of leaves (Figure 1c). High levels of salt concentrations may also lead to rapid leaf falling. A. marina seedlings produced the leaves relatively small, resulted the chances are very high the leaves to fall. While the leaves of $R$. stylosa generally have a large size which is almost the same as the old leaves.

Effect of salinity on the seedling biomass Seedling biomass was studied in relation to varied salt concentration and its subsequent recovery in a secretor species, A. marina and a non-secretor species $R$. stylosa as shown in Figure 3, Figure 4, Figure 5, and Figure 6. No statistical difference was noted in wet and dry weight of $A$. marina leaves, stems and roots under salinity (Figure 3, Figure 5) and found only at 2.0\% $\rightarrow$ $0.0 \%$ after transfer upon fresh water (Figure 3). Similarly, high salinity followed by freshwater decreased significantly wet and biomass of $R$. stylosa leaves and roots, but not in wet weight and biomass of $R$. stylosa stems (Figure $4 \mathrm{c}-\mathrm{d}$ ). Salinity and its subsequent to freshwater increased the ratio of shoot to root and ratio of stem to root in A.marina, however, significantly was noted at 3 and $2 \%$, respectively (Figure $5 \mathrm{c}-\mathrm{d}$ ). By contrast, salinity and re-adaptation decreased ratio of shoot to root in $R$. stylosa and no significant change in the case of ratio of stem to root in this species (Figure $6 \mathrm{c}-\mathrm{d}$ ). In case of $A$. marina, ratios of root mass to leaf mass were higher at high salinity, indicating that either water or nutrient limitations may have limited seedling

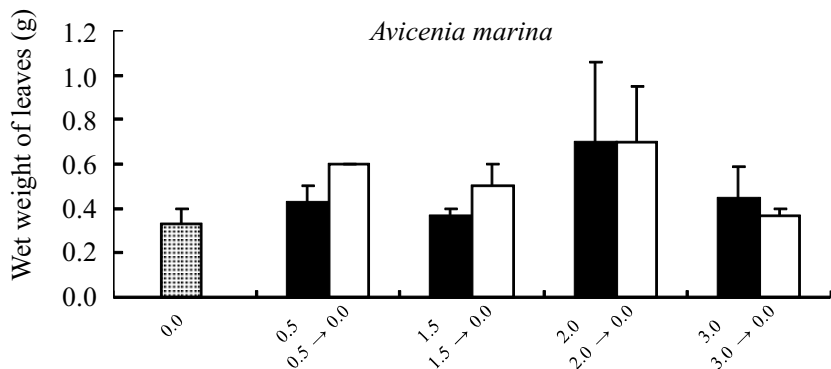

Salt concentration $(\%)$

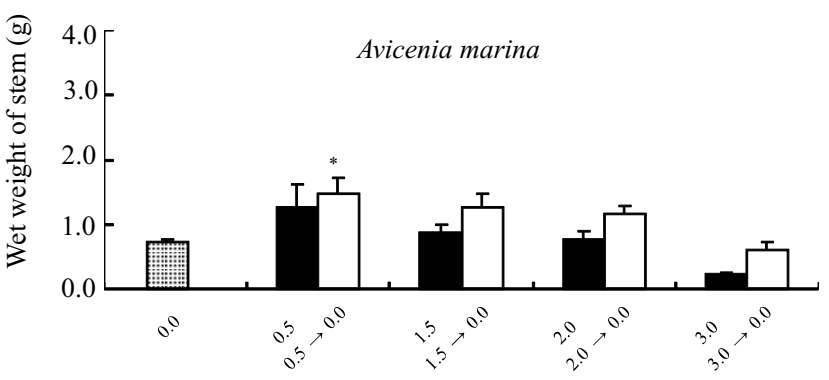

c

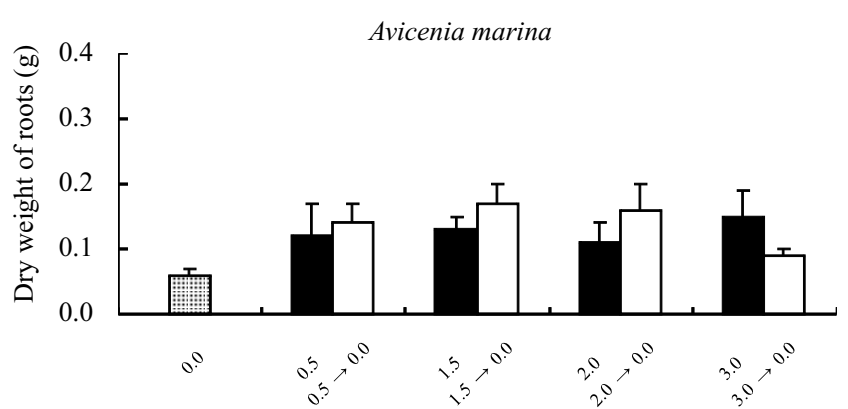

b

Salt concentration $(\%)$

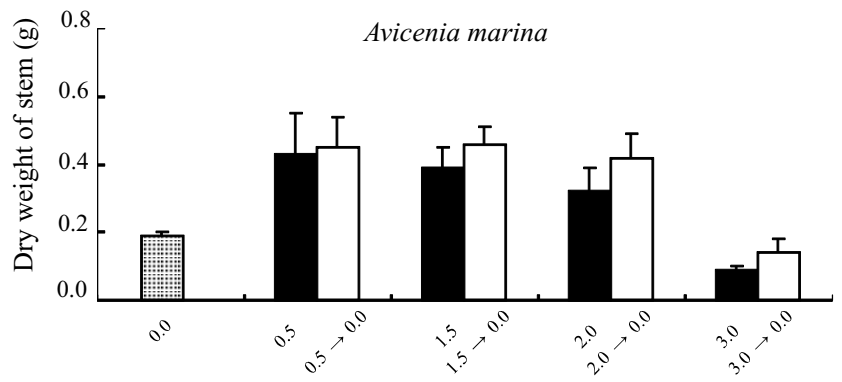

Salt concentration $(\%)$

Figure 3 Effect of salinity and subsequent re-adaptation to fresh water on wet weight of leaves (a), dry weight of leaves (b), wet weight of stems (c), and dry weight of stems (d) of Avicenia marina seedlings. The data are expressed as the means $\pm \mathrm{SE}$

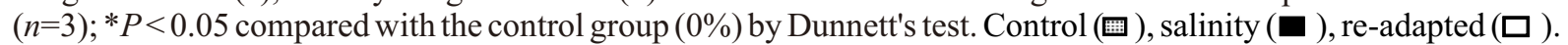



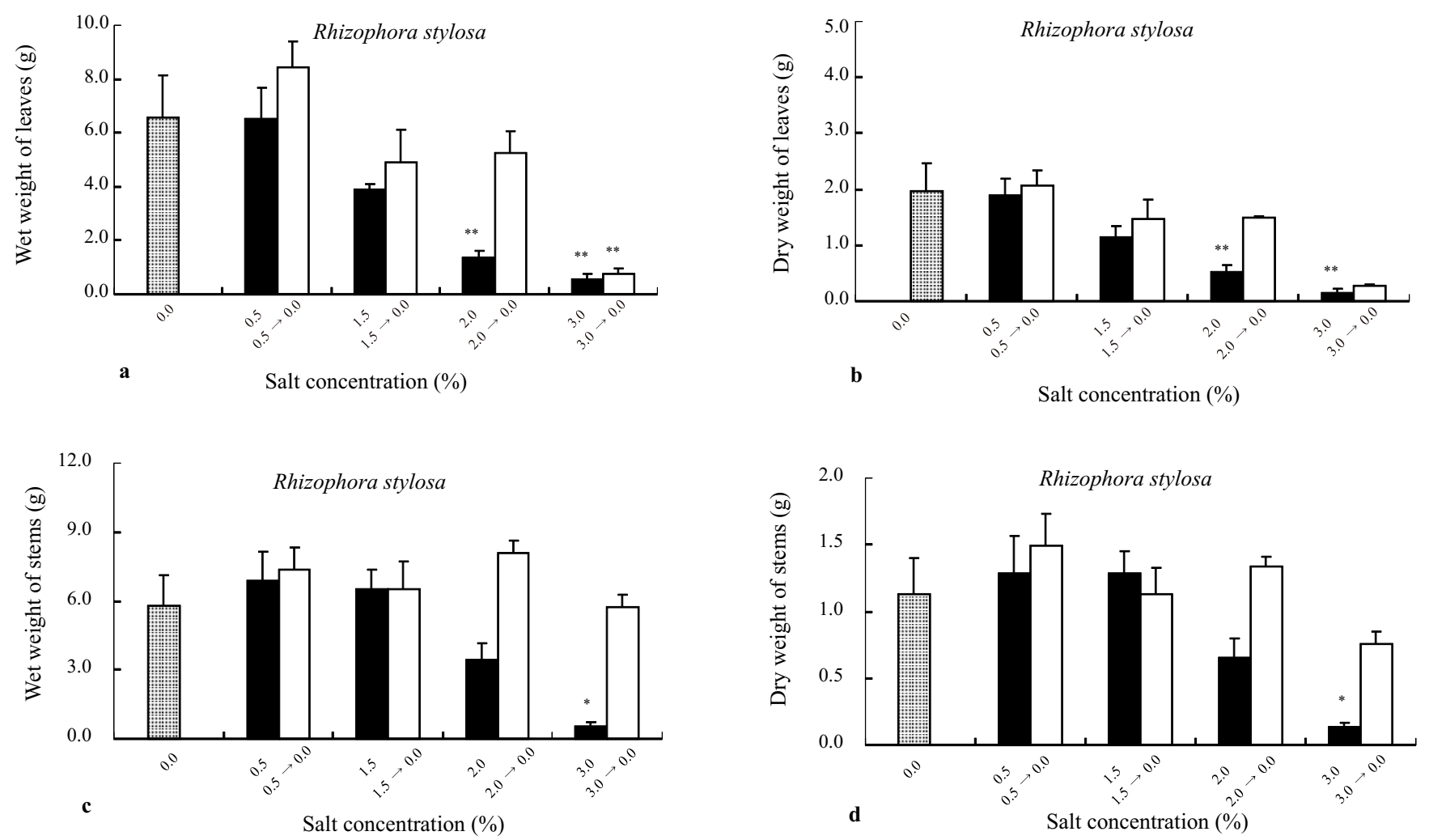

Figure 4 Effect of salinity and subsequent re-adaptation to fresh water on wet weight of leaves (a), dry weight of leaves (b), wet weight of stems (c), and dry weight of stems (d) of Rhizophora stylosa seedlings. The data aare expressed as the means $\pm \mathrm{SE}$ $(n=3) ; * * P<0.01, * P<0.05$ compared with the control group $(0 \%)$ by Dunnett's test. Control (四), salinity ( $\square$ ), re-adapted (口).
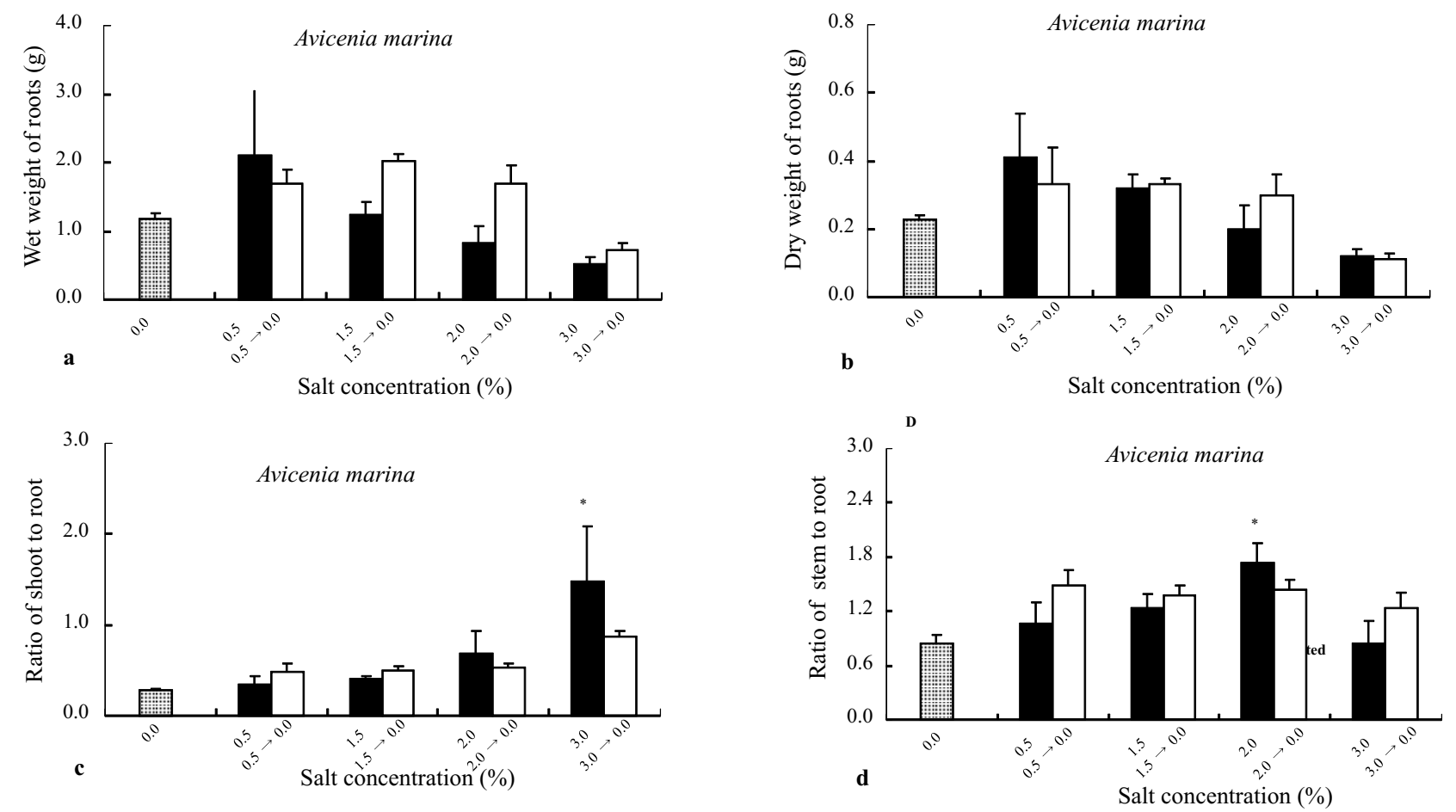

Figure 5 Wet weight of roots (a), dry weight of roots (b), ratio of shoot to root (c) and ratio of stem to root (d) of Avicenia marina grown under salinity and after re-adaptation from salinity. The data are expressed as the means $\pm \mathrm{SE}(n=3) ;{ }^{*} P<0.05$ compared with the control group $(0 \%)$ by Dunnett's test. Control (眐), salinity ( $\boldsymbol{\square})$, re-adapted( $\square)$. 

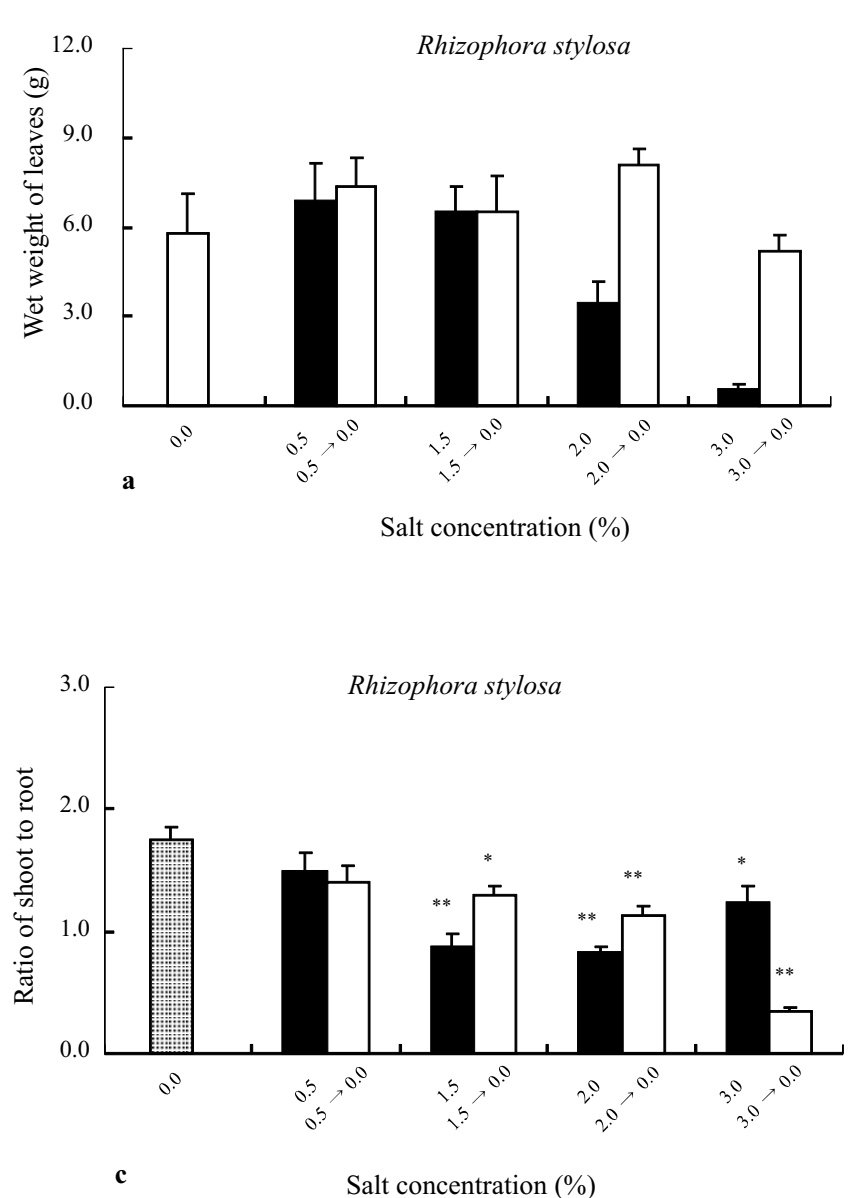
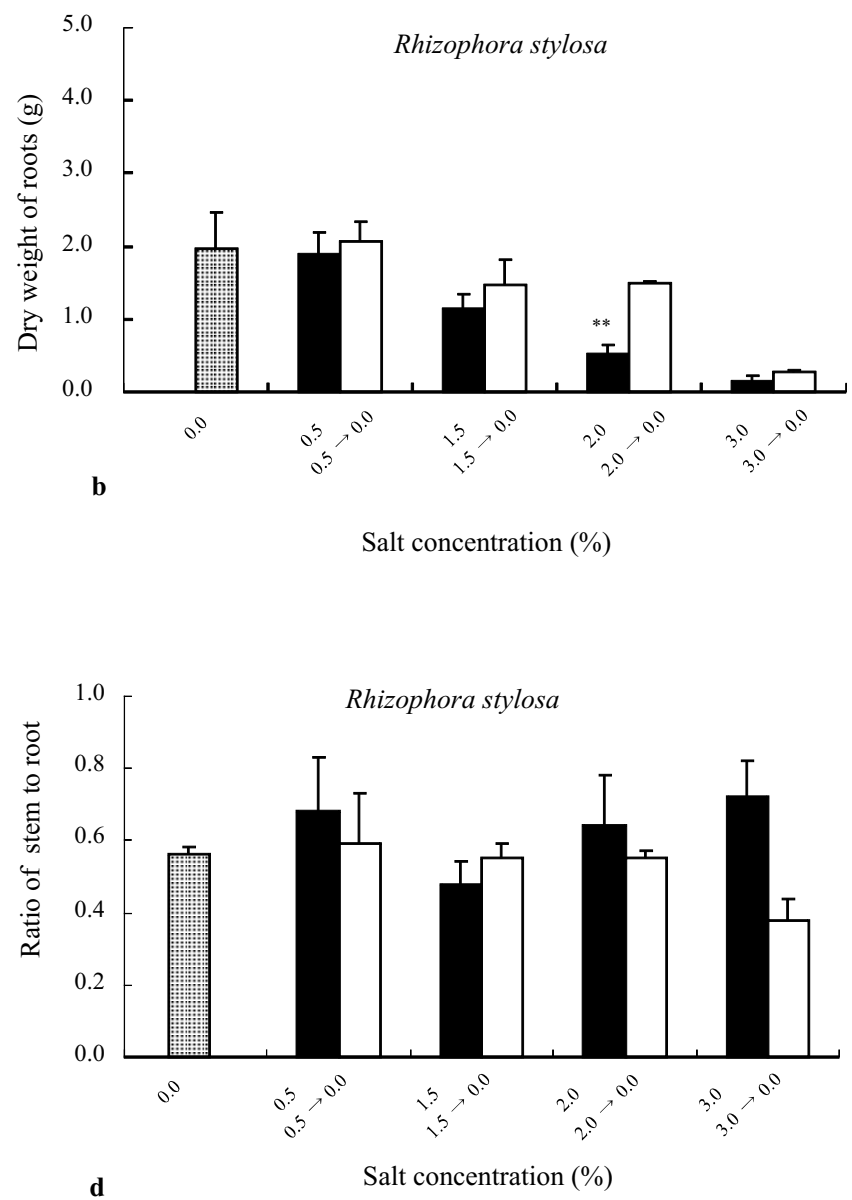

Figure 6 Wet weight of roots (a), dry weight of roots (b), ratio of shoot to root (c), and ratio of stem to root (d) of Rhizophora stylosa grown under salinity and after re-adaptation from salinity. The data are expressed as the means $\pm \operatorname{SE}(n=3) ; * * P<0.01$,

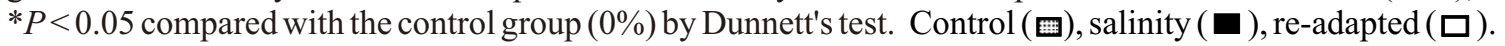

growth at high salinity (Figure 5c). Furthermore, our results suggested that roots of $A$. marina may transport more oxygen into soil than those of $R$. stylosa. Therefore, it seems that $A$. marina might have more tolerance to salt and water stress than R. stylosa.

Biomass production of $A$. marina and $R$. stylos $a$ seedlings was stimulated at 2 and $0.5 \%$ salt concentration. The wet and dry weight of the mangrove seedlings was changed in the same manner as the growth of plants upon salt and fresh water treatment. Similar results of mangrove seedling biomass were obtained in $C$. tagal and $R$. mucronata from Pakistan (Khan \& Aziz 2001). Biomass of $R$. stylosa was more accumulated than that found in A. marina. Our present findings supported our previous results on the salt tolerance of 4 mangrove seedlings studied in our laboratory increases in the order of B. gymnorrhiza $<K$. candel $<R$. stylosa $<A$. marina, which is in accordance with their habitat zonation. $A$. marina grows closest to sea, whereas $B$. gymnorrhiza is distributed rather inland than in the coastal area compared to $R$. stylosa and $K$. candel, indicating B. gymnorrhiza was less tolerant to salt stress (Basyuni et al. 2007; 2012a).
A. marina had lower shoot/root biomass ratio (S/R) than R. stylosa (Figure 5c, Figure 6c), indicating that the species more tolerant to salt or water stress would allocate more biomass to roots. This is similar to the conclusion by Ye et al. (2003) that $K$. candel, a species relatively more sensitive to low redox potentials, had lower root weight ratio (that is higher shoot/root biomass ratio) than B. gymnorrhiza. The shoot/root biomass ratio varies with changing adaptive conditions of internal and external plant environment (Ye et al.2003).

\section{Conclusion}

Salinity and subsequent recovery to fresh water treatments influenced the growth and biomass of the two mangrove seedlings. The current study clearly showed that within the range of treatments used, 2.0 and $0.5 \%$ were the optimal salinity by A. marina and $R$. stylosa, respectively, for growth, providing important information for mangrove rehabilitation in North Sumatra, Indonesia particularly how to select the appropriate site for mangrove replanting. Furthermore, from parameter used, 
this study indicated that the salt tolerance of the mangrove seedlings, the order is A. marina $>R$. stylos $a$, which is in accordance with habitat zonation of mangrove. The biomass of the mangrove seedlings was changed in the same manner as the growth of plants upon salt and fresh water treatment, suggesting the importance of mangrove adaptation withstand salt and/or water stress.

\section{Acknowledgements}

A part of this study was supported by a Grant-in-Aid for a Fundamental Grant (Contract No. 4268/UN5.1.R/KEU/2013 to $\mathrm{MB}$ ) from the Directorate for Research and Community Service, Ministry of Education and Culture, Republic of Indonesia.

\section{References}

Ball MC. 1988. Salinity tolerance in the mangroves, Aegiceras corniculatum and Avicennia marina.Water use in relation to growth, carbon partitioning and salt balance. Australian Journal of Plant Physiology 15:447-464. http://dx.doi.org/10.1071/PP9880447.

Ball MC. 2002. Interactive effects of salinity and irradiance on growth: implications for mangrove forest structure along salinity gradients. Trees 16: 126-139. http://dx.doi.org/10.1007/s00468-002-0169-3.

Basyuni M et al. 2007. Triterpene synthases from the okinawan mangrove tribe, Rhizophoraceae. the Federation of European Biochemical Societies Journal 274:5028-5042. http://dx.doi.org/10.1111/j.17424658.2007.06025.x.

Basyuni M et al. 2009. Expression of terpenoid synthase mRNA and terpenoid content in salt stressed mangrove. Journal of Plant Physiology 166: 1786-1800. http://dx. doi.org/10.1016/j.jplph.2009.05.008.

Basyuni M et al. 2011. Isolation of salinity tolerance genes from roots of mangrove plant, Rhizophora stylosa Griff., using PCR-based suppression subtractive hybridization. Plant Molecular Biology Reporter 29: 533-543. http://dx.doi.org/10.1007/s11105-010-02572.

Basyuni M, Baba S, Kinjo Y, Oku H. 2012a. Salinity increases the triterpenoid content of a salt secretor and a non-salt secretor mangrove. Aquatic Botany 97:17-23. http://dx.doi.org/10.1016/j.aquabot.2011.10.005.

Basyuni M et al. 2012b. Salt-dependent increase in triterpenoids is reversible upon transfer to fresh water in mangrove plants Kandelia candel and Bruguiera gymnorrhiza. Journal of Plant Physiology 169:1903-1908. http://dx.doi.org/10.1016/j.jplph.20 12.08.005.

Burchett MD, Clarke CJ, Field CD, Pulkownik A. 1989. Growth and respiration in two mangrove species at a range of salinities. Physiologia Plantarum 75:
299-303. http://dx.doi.org/10.1111/j.1399-3054.1989. tb06185.x.

Clough BF. 1984. Growth and salt balance of the mangroves Avicennia marina (Forssk.) Vierh. and Rhizophora stylosa Griff. in relation to salinity. Australian Journal of Plant Physiology 11: 419-430. http://dx.doi.org/10. 1071/PP9840419.

Downton WJS. 1982. Growth and osmotic relations of the mangrove Avicennia marina, as influenced by salinity. Australian Journal of Plant Physiology 9: 519-528. http://dx.doi.org/10.1071/PP9820519.

Duke NC et al. 2007. A world without mangroves? Science 317:41-42. http://dx.doi.org/10.1126/science.317. $5834.41 \mathrm{~b}$.

Feller IC et al. 2010. Biocomplexity in mangrove ecosystems. Annual Review of Marine Science 2: 395-417. http://dx.doi.org/10.1146/annurev.marine. 010908.163809.

Flowers TJ, Colmer TD. 2008. Salinity tolerance in halophytes. New Phytologist 179: 945-963. http://dx.doi.org/10.1111/j.1469-8137.2008.02531.x.

Gilman EL, Ellison J, Duke NC, Field C. 2008. Threats to mangroves from climate change and adaptation options: A review. Aquatic Botany 89: 237-250. http://dx.doi.org/10.1016/j.aquabot.2007.12.009.

Giri C et al. 2011. Status and distribution of mangrove forests of the world using earth observation satellite data. Global Ecology and Biogeography 20:154-159. http://dx.doi.org/10.1111/j.1466-8238.2010.00584.x.

Hutahaen EE, Kusmana C, Dewi HR. 1999. Study on growth capability of mangrove forest seedling of Rhizophora mucronata, Bruguiera gymnorrhiza and Avicennia marina species on various levels of salinity. Jurnal Manajemen Hutan Tropika 5 (1): 77-85.

Kathiresan K, Rajendran N. 2002. Growth of a mangrove (Rhizophora apiculata) seedlings as influenced by GA3, light and salinity. Revista de Biología Tropical 50: $525-530$.

Khan MA, Aziz I. 2001. Salinity tolerance in some mangrove species from Pakistan. Wetlands Ecology and Management 9: 219-223. http://dx.doi.org/10.1023/A: 1011112908069

Krauss KW et al. 2008. Environmental drivers in mangrove establishment and early development: A review. Aquatic Botany 89: 105-127. http://dx.doi.org/10. 1016/j.aquabot.2007.12.014.

Krauss KW, Ball MC. 2013. On the halophytic nature of mangroves. Trees 27: 7-11. http://dx.doi.org/10.1007/ s00468-012-0767-7. 
Lugo A, Snedaker SC. 1974. The ecology of mangroves. Annual Review of Ecology and Systematics 5:39-64. http://dx.doi.org/10.1146/annurev.es.05.110174.0003.

Naidoo G. 2006. Factors contributing to dwarfing in the mangrove Avicennia marina. Annal of Botany 97: 1095-1101. http://dx.doi.org/10.1093/aob/mcl064.

Oku H, Baba S, Koga H, Takara K, Iwasaki H. 2003. Lipid composition of mangroves and its relevance to salt tolerance. Journal of Plant Research 116: 37-45. http://dx.doi.org/10.1007/s10265-002-0069-z.

Schneider CA, Rasband WS, Eliceiri KW. 2012. NIH Image to ImageJ: 25 years of image analysis. Nature Methods 9:671-675. http://dx.doi.org/10.1038/nmeth.2089.

Scholander PF, Hammel HT, Hemmingsen E, Garey W. 1962. Salt balance in mangroves. Plant Physiology 37:722-729. http://dx.doi.org/10.1104/pp.37.6.722.

Tomlinson PB. 1986. The Botany of Mangroves. London: Cambridge University Press.
Wang WQ, Ke L, Tam NFY, Wong YS. 2002. Changes in the main osmotia during the development of Kandelia candel hypocotyls and after mature hypocotyls transplanted in solutions with different salinities. Marine Biology 141:1029-1034. http://dx.doi.org/10. 1007/s00227-002-0951-1.

Wang W et al. 2011. Mangroves: obligate or facultative halophytes? A review. Trees 25:953-963. http://dx.doi.org/10.1007/s00468-011-0570-x.

Yan Z, Wang W, Tang D. 2007. Effect of different time of salt stress on growth and some physiological processes of Avicennia marina seedlings. Marine Biology 152:581-587. http://dx.doi.org/10.1007/s00227-0070710-4.

Ye Y, Tam NFY, Wong YS, Lu CY. 2006. Growth and physiological responses of two mangrove species (Bruguiera gymnorrhiza and Kandelia candel) to waterlogging. Environmental and Experimental Botany 49: 209-221. http://dx.doi.org/10.1016/S0098-8472 (02)00071-0. 